\title{
Femtogram per Milliliter per Kilogram per Meter Squared
}

National Cancer Institute

\section{Source}

National Cancer Institute. Femtogram per Milliliter per Kilogram per Meter Squared. NCI Thesaurus. Code C119336.

A unit of concentration equal to femtogram per milliliter, divided by kilograms per meter squared. 